\title{
Creating a Future of Our Own Design: The International Indigenous HealthFusion Team Challenge as a Promising Practice to Support Indigenous Students in Health Fields
}

\author{
Shandryn Kozin, Hailey Matheson, Tatyana Daniels, Brittany Mullin, Bret Watts, Katie Skelton, \\ Janene Erickson, Drew St. Laurent, Kate Jongbloed, Evan Adams
}

\section{A R T I C L E I N F O}

Keywords:

Indigenous health

Indigenous students

Allied health

Indigenous health workforce

Capacity building

Reconciliation

https://doi.org/10.32799/ijih.v16i1.33217

\begin{abstract}
A B S T R A C T
Training and recruitment of First Nations and Indigenous health professionals is part of reconciliation, addressing health disparities and embedding cultural safety and humility into the health ecosystem of the province of British Columbia (BC), Canada. Calls to develop the First Nations and Indigenous health workforce are articulated within the Truth and Reconciliation Commission of Canada's Call to Action 23, BC's Transformative Change Accord: First Nations Health Plan, and the seven directives that guide the work of the First Nations Health Authority in $\mathrm{BC}$ and its health governance partners. This article brings forward the voices of current Indigenous students training in allied health professions at the University of British Columbia and their Indigenous mentors who participated in the 2018 International Indigenous HealthFusion Team Challenge in Sydney, Australia. The Challenge represents a promising practice in training Indigenous health professionals here in BC as it: (1) Affirmed their Indigenous identity, knowledge, and aspirations, supporting them to become more "visible" as Indigenous students; (2) Created a space where both Indigenous and mainstream health discipline knowledges were encouraged, valued, and respected; (3) Provided opportunity to connect with Indigenous peers and health leaders; and (4) Built students' confidence to take on leadership roles. First Nations and Indigenous students studying in health fields represent the future of BC's health and wellness ecosystem that brings together the best of Indigenous and mainstream healing approaches. Creating opportunities for students to grow as Indigenous health leaders is part of reconciliation and the new relationship represented by the $\mathrm{BC}$ First Nations Health Governance Structure.
\end{abstract}

A UTHOR INFO

For Team Smoked Salmon:

Shandryn Kozin, Kinosao Sipi Cree Nation, School of Audiology and Speech Sciences, University of British Columbia (UBC)

Hailey Matheson, Peguis Nation, School of Social Work, UBC

Tatyana Daniels, Gitxsan Nation, Dietetics, Faculty of Land and Food Systems, UBC

Brittany Mullin, Upper Similkameen Indian Band, Dental Hygiene Degree Program, Faculty of Dentistry, UBC

Bret Watts, Nuu-chah-nulth, School of Kinesiology, UBC 
INTERNATIONAL JOURNAL OF INDIGENOUS HEALTH

Katie Skelton, Henvey Inlet First Nation, Partnership Development \& Projects, CEO Office, First Nations Health Authority (FNHA)

Janene Erickson, Nak'azdli Whut'en, Partnership Development \& Projects, CEO Office, FNHA

Drew St. Laurent, Métis, Senior Operations Manager, Centre for Excellence in Indigenous Health, UBC

Kate Jongbloed, Listener \& Writer, CEO Office, FNHA

Dr. Evan Adams, Tla'amin Nation, Chief Medical Officer, FNHA. Email: evan.adams@canada.ca

\section{Acknowledgements}

We acknowledge the Gadigal people of the Eora Nation in Sydney where we gathered, as well as the Traditional Owners of country throughout Australia, and recognize their continuing connection to land, waters, and culture. We pay our respects to their Elders past, present, and emerging. We also acknowledge the territories of the Coast Salish Peoples, and all the medicines within them, where we live, work, and go to school. We extend our sincere gratitude to Mr. Joe Gallagher, $k^{w} u n \partial m \varepsilon n$, who served as a judge during the Challenge and who provides support and guidance to all of us.

\section{Introduction}

First Nations and Indigenous ${ }^{1}$ people have an important role as professionals in both mainstream and traditional health and wellness services offered in the province of British Columbia (BC), Canada. Training and recruitment of First Nations and Indigenous health professionals is part of reconciliation, as well as hardwiring cultural safety and humility into BC's health ecosystem (First Nations Health Authority [FNHA], 2016b; Truth and Reconciliation Commission of Canada [TRC], 2015). A strong Indigenous health workforce supports self-determination by increasing First Nations' capacity to directly deliver services to their people and communities, as well as transforming the mainstream system to uphold First Nations and Indigenous perspectives of health and wellness (BC Assembly of First Nations et al., 2006). It represents a pathway to addressing health inequities and negative social determinants of health resulting from colonialism (Curtis, 2016; FNHA, 2016a; Reading, 2015). Though many First Nations and Indigenous people in BC have achieved success within the province's health ecosystem, colonialism continues to negatively impact educational attainment and employment. Further, data have not been collected on Indigenous representation in BC's health workforce, including within the province's 21 regulated health professions. As a result, First Nations and Indigenous health professionals remain invisible in health workforce statistics, and it is likely they are underrepresented.

Commitments to strengthening the Indigenous health workforce are embedded within agreements underpinning First Nations self-determination over health in BC. With the signing of

\footnotetext{
${ }^{1}$ In BC, where health governance comes from BC First Nations but services are also delivered to diverse Indigenous people living in these territories, we recognize that unique context by using the term, "First Nations and Indigenous people."
} 
the 2005 Transformative Change Accord, First Nations in BC and the federal and provincial governments committed to a new relationship based on mutual respect and recognition of Indigenous Peoples' inherent rights to make decisions about things that affect them (Government of British Columbia et al., 2005). The 2006 Transformative Change Accord: First Nations Health Plan that followed set out a plan to close the health gap between First Nations and other BC residents (BC Assembly of First Nations et al., 2006). It included specific action items to dedicate postsecondary seats for First Nations and Indigenous students in order to increase the number of trained Indigenous health care professionals (BC Assembly of First Nations et al., 2006). To reach this goal, postsecondary institutions and Indigenous communities must work to improve access, participation, and success of Indigenous learners in postsecondary health care programs (BC Assembly of First Nations et al., 2006).

A plan to establish a First Nations Health Governance Structure was set out in the 2007 First Nations Tripartite Health Plan (First Nations Leadership Council et al., 2007). This led to a landmark decision by BC First Nations in 2011 to retake control over health and wellness from the Government of Canada and create a one-of-a-kind health governance partnership between BC First Nations and the federal and provincial governments (BC Ministry of Health et al., 2011; FNHA \& Assembly of First Nations, 2013; FNHA \& First Nations Health Council [FNHC], 2011). BC First Nations established the seven directives outlining fundamental standards of the new health governance structure (FNHA \& FNHC, 2011, 2012). Directive 5 focuses specifically on development of human and economic capacity, including developing "current and future health professionals at all levels through a variety of education and training methods and opportunities" (FNHA \& FNHC, 2011, p. 11).

Calls to build the Indigenous health workforce were echoed nationally by the Truth and Reconciliation Commission (TRC) of Canada (TRC, 2015). The TRC report emphasized the importance of long-term investment in Indigenous communities as part of healing and reconciliation, including through training of Indigenous health and social service professionals (TRC, 2015). Call to Action 23 states, "We call upon all levels of government to: i. Increase the number of Aboriginal professionals working in the health-care field. ii. Ensure the retention of Aboriginal health-care providers in Aboriginal communities" (TRC, 2015, p. 164).

Fulfilling these commitments requires investment and action to recruit, enroll, and support First Nations and Indigenous learners in health fields, including nursing, medicine, and allied health (FNHA, 2016a). This article reflects on one promising practice in training of Indigenous health professionals. It brings forward the voices of current Indigenous students training in allied health fields at the University of British Columbia (UBC), and their Indigenous mentors, who participated in the 2018 International Indigenous HealthFusion Team Challenge.

\section{Methods}

The International Indigenous HealthFusion Team Challenge is a 3-day event where teams of five Indigenous students from a variety of health disciplines create a care plan in response to a hypothetical complex Indigenous case study. The 2018 Challenge took place as part of the 
International Indigenous Allied Health Forum in Sydney, Australia, on the traditional territories of the Gadigal people of the Eora Nation, from December 1 to 3. Five Australian, one Aotearoa/New Zealand, and - for the first time — one Canadian team competed. Following the event, the Canadian team debriefed and collaborated to develop this promising practice article with full authorship of both students and mentors.

\section{Introducing "Team Smoked Salmon," Sponsored by the FNHA and UBC}

The FNHA partnered with UBC Health and UBC's Centre for Excellence in Indigenous Health to form a team. Overall, 91 Indigenous students enrolled in allied health disciplines at UBC were eligible to apply. Twenty-six applications were received. Five students were intentionally selected from different programs to support interdisciplinary collaboration. They named themselves "Team Smoked Salmon." Students were joined by four Indigenous mentors and one Indigenous judge from FNHA and UBC (Figure 1).

\section{Figure 1}

Students, Mentors, and Judge from UBC and FNHA

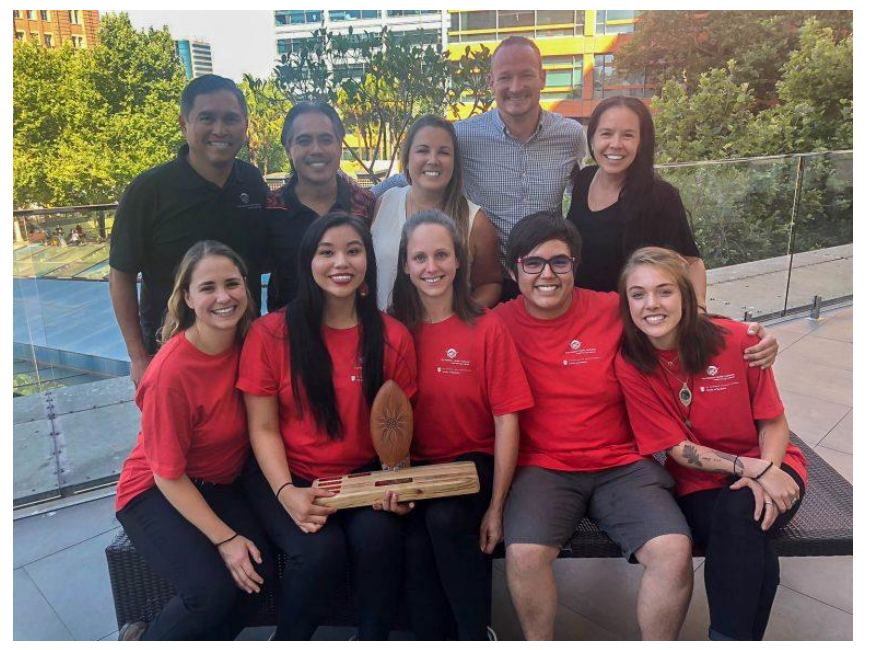

Note. Front row (students): Shandryn Kozin, Kinosao Sipi Cree Nation (UBC Audiology); Tatyana Daniels, Gitxsan Nation (UBC Dietetics); Brittany Mullin, Upper Similkameen Indian Band (UBC Dental Hygiene); Bret Watts, Nuu-chah-nulth (UBC Kinesiology); Hailey Matheson, Peguis Nation (UBC Social Work). Back row (mentors and judge): Joe Gallagher, Tla'amin Nation (former Chief Executive Officer, FNHA); Dr. Evan Adams, Tla'amin Nation (Chief Medical Officer, FNHA); Katie Skelton, Henvey Inlet First Nation (Partnership Development \& Projects, CEO Office, FNHA); Drew St. Laurent, Métis (Senior Operations Manager, UBC Centre for Excellence in Indigenous Health); Janene Erickson, Nak'azdli Whut'en (Partnership Development \& Projects, CEO Office, FNHA). 


\section{Competition Details}

Teams were challenged to demonstrate leadership, knowledge, and collaboration to respond to a complex Indigenous health case study in which two young siblings had been injured in an all-terrain vehicle accident. Students developed a health care management plan that supported the mental, spiritual, emotional, and physical health and wellness of the children and their family through a complex trauma. After 3 days of work, they presented their plan to an international panel of judges.

Team Smoked Salmon won first prize with their plan that expertly brought together the best of both worlds - their disciplinary expertise from UBC learning, along with the Indigenous teachings they carry and continue to learn. The team's approach incorporated the BC First Nations Perspective on Health and Wellness, and was guided by cultural safety and humility (FNHA, n.d., 2016b). Tatyana was also honoured with a Leadership Award.

\section{Results and Discussion}

After returning home, Team Smoked Salmon shared how participating in the Challenge had impacted them, their journey at UBC, and their role within their profession, as it: (1) affirmed their Indigenous identity, knowledge, and aspirations, supporting them to become more "visible" as Indigenous students; (2) created a space where both Indigenous and mainstream health discipline knowledges were encouraged, valued, and respected; (3) provided opportunity to connect with Indigenous peers and health leaders; and (4) built students' confidence to take on leadership roles.

\section{Affirmed Their Indigenous Identity, Knowledge, and Aspirations, Supporting Them to Become More "Visible" as Indigenous Students}

Indigenous students remain a minority at UBC. With only 91 Indigenous students enrolled in the UBC allied health disciplines, many face being the only Indigenous person in their program or classroom. Team Smoked Salmon students spoke about how they have been hesitant to share their Indigenous identity and experiences in the context of their UBC studies. Involvement with the Challenge gave them more confidence to be more "visible" as Indigenous students and future health professionals.

Janene (Mentor): [The Challenge] was developed by Indigenous people for Indigenous people. Day 1 provided students with opportunities to attend presentations and workshops delivered by Indigenous people in their fields of interest around the world. Students were supported, encouraged, and challenged to apply their life knowledge and experiences (including their university training) to develop a wholistic short-, medium-, and long-term health care plan. The forum was infused with Indigenous ways of knowing and being-supporting students to be confident in who they are and what they've learned-and to bring that into the system so they feel empowered to do things the way they know they should be done. That's system transformation. 
Students also shared that the experience helped affirm they are on a path that will address some harms and inequities faced by Indigenous people and is related to their field of study. For example, Shandryn spoke about barriers accessing audiology services, particularly in remote communities. She shared how hearing is an essential part of family relationships, and that increasing access to audiology services for Indigenous people is fundamental to her professional aspirations. Hailey reflected on the harms the social work profession has caused in Indigenous communities, and how learning outside the classroom helped her to honour and uphold Indigenous self-determination in child welfare during her practicum placement. Both students shared that the Challenge strengthened their confidence by creating a community of other Indigenous students and mentors who support them, as well as by demonstrating how Indigenous and disciplinary knowledge can work together.

Hailey (Student): This experience gave me more courage to be able to say what I know and what I think as an Indigenous person and to talk about this with my peers. We have six Indigenous people in our class-the most we've ever had. Before this experience, we would informally gather to talk, but we now come together and meet every couple of weeks with an Indigenous professor. Together, we work on Indigenizing the school, trying to bring our peers in on cultural pieces, and also being able to be confident in speaking to them as Indigenous people and as future health professionals. We also focus on having confidence in knowing the importance of our teachings for them to hear, hoping that what we share is helping people learn, especially social workers who are going to be working with Indigenous people, and have to compensate for past and present harms. This is coming at a really good time because at least at UBC, the School of Social Work is trying to see how we can put better social workers out there. How do we put professionals out there who don't keep doing what continues to happen and who aren't going to keep taking Indigenous kids away? How do we go forward, how do we reconcile what we do as a profession, how do we go forward and do different and do better? This experience made me feel like I have a significant voice there, and that it's valid, that it's not just an opinion, it's important.

\section{Created a Space Where Both Indigenous and Mainstream Health Discipline Knowledges Were Encouraged, Valued, and Respected}

Students explained that the Challenge provided space where both the Indigenous and disciplinary knowledge they brought to the table was valued. They shared that in other settings, one or the other is often given more weight. At worst, in mainstream settings the teachings they carry from family, Elders, and Knowledge Keepers may be sidelined completely. As a result, students shared that they are cautious about integrating Indigenous perspectives and understandings in case these are treated with disrespect. Participating in the Challenge affirmed that both sources of knowledge could be applied, and were, in fact, invaluable.

Katie (Mentor): Students and mentors represented a really diverse group in terms of where they come from and also their professional expertise. What stuck with me is how 
quickly students could come together to work with a shared set of values that made sense to them-wholistic health and wellness, self-determination, working with and not for an Indigenous family — despite their different backgrounds. The Challenge was a way to actually apply these values that are foundational in many of our cultures, within a professional setting. That is not an opportunity that is provided in a mainstream classroom, but it is essential to how the health system needs to change to meet the needs of First Nations and Indigenous people.

For example, Tatyana shared that "cultural competency" is one of the competencies required of registered dieticians, but how a UBC student would develop this competency in advance of the qualifying exam was not clear. The Challenge provided an opportunity for applied learning in cultural safety and humility.

Tatyana (Student): I feel like I've gained more self-confidence in my career choice and more confidence working with an interprofessional team. Meeting so many Indigenous students within allied health programs, who face similar experiences and difficulties as we do, was inspiring. Being able to discuss issues that we face within the Western educational system was therapeutic in a sense, knowing that there are others who feel the same but also knowing that we need to promote change within these institutions. Having the opportunity to go to this Indigenous case study competition that I didn't even know existed was invaluable to get the hands-on experience of a complex case study while integrating an Indigenous perspective into our Western education. This is something we would never get to do in a standard curriculum. I've always talked about doing this integration of Indigenous and Western knowledge in my career, but I had no actual experience, so how was I to know if I could actually do it? This showed me that I could help bring these two worlds together in my profession ... and as a bonus, we even won!

\section{Provided Opportunity to Connect With Indigenous Peers and Health Leaders}

Students emphasized the power of connecting with a large group of supportive Indigenous peers, health leaders, and professionals from three countries. They spoke about how mentors offered support that went beyond achieving specific Challenge goals. Rather, mentors offered respect and trust in each student as a person, as well as a commitment to their overall growth and development as Indigenous health professionals.

Hailey (Student): Something that was powerful for me was to be in a room with so many Indigenous people who are passionate, who are hopeful, who have dreams for their communities-and who also were open to sharing that with us. It felt like they were there for us, obviously to help us with this project, but it also felt like they were just there for us as individuals.

Brittany (Student): Due to colonization, I was not raised with connection to my Indigenous heritage. Over the past few years, I began to reconnect with my traditional 
family, but I still lacked experience with Indigenous perspectives and teachings. Through my UBC education, I became aware of the need for Indigenous perspectives to be integrated into health care settings to promote cultural safety and initiate policy change to close gaps in health status. I wanted to make a difference but was unsure of how to connect with other Indigenous health advocates to be part of creating change. I was also unsure if my input would be welcomed amongst Indigenous communities; as someone raised without Indigenous influence, I considered myself an outsider and felt caught between two worlds. Being welcomed by, and able to connect with, Indigenous peers and leaders helped solidify my personal Indigenous identity, increase my confidence to seek more teachings from Knowledge Keepers, and see new possibilities within the diverse careers of health professionals.

For most students, it was the first time they had had an opportunity to connect with and build relationships with established Indigenous health professionals. The impact was profound as it contributed to feelings of self-worth, interconnectedness, and being part of a larger movement of positive action and transformation in Indigenous health. A year on, both mentors and students note that relationships formed within Team Smoked Salmon and the wider group of Challenge participants are ongoing. This includes engagement with cultural activities, support for students' career and educational endeavours, and opportunities for leadership.

Drew (Mentor): As Indigenous mentors, we connected with students about where they were at in their own journeys - their educational journeys, career journeys, and also personal journeys related to their identity. Each mentor brought their own professional expertise, whether that was in public health or postsecondary education or medicine, as well as personal experiences and knowledge as an Indigenous person. The Challenge format allowed us to build a foundation of connection that was safe and comfortable. These relationships didn't end after the competition. I still keep in contact with students from Australia and New Zealand about opportunities here in Canada, and also sharing what we're doing with cultural safety here at UBC. More personally, some students with mixed ancestry struggling to find their identity were also interested to learn about how Métis culture and heritage is understood and celebrated here, which I could share from my experience. I am also regularly still in touch with the UBC students. Writing reference letters, sharing opportunities, navigating challenges, providing feedback, and being a sounding board. When I think about the work they did together, in an interdisciplinary team, to support a family's health plan, I am excited for the contributions they will make to the health of our communities and Nations.

\section{Built Students' Confidence to Take on Leadership Roles}

Students discussed actions they had taken since returning that reflected the lessons and experiences of the Challenge. For example, Shandryn shared that the experience prompted her to take on a role within UBC's School of Audiology and Speech Sciences' reconciliation and cultural safety initiatives, as well as within her future career path. For her, this includes being a 
panelist at this year's Speech and Hearing BC conference. She addressed professionals, presenters, and exhibitors on the future of serving Indigenous communities in BC and bridging her Indigenous and audiologic perspectives.

Shandryn (Student): Evan, one of our mentors, encouraged me to take the panelist position this fall. I would have never even thought to take an opportunity like this before the Challenge. Usually, I would have said "no thanks." I'd much rather have one-on-one discussions. They feel safer to me. But I have an obligation, an opportunity to take what my mentors, Elders, and peers have taught me, to make change in all aspects of my pursuits. I'm still learning how to use my voice to make change, but I'm very excited to see where it can take the future of health care in audiology. I want to use multiple lenses of knowledge to provide the best care I can, beyond the audiological influences of care, and alongside a focus of wholistic well-being. I think of my heritage as a very personal value; sometimes it's hard to put yourself out there and be vulnerable. This experience has taught me the value of consenting to learn on public platforms even when it seems beyond your capabilities. I really can take on and change the way that my school and allied health professionals incorporate the value of Indigenous knowledge into their clinics. It is still under development, but there is so much value in the baby steps. I want and feel a need to be a part of that. This trip was beyond powerful. It was a time to connect a large group of supportive Indigenous peers, health leaders, and professionals; a reminder of the work that needs to be done. The work we can do. Where the future can go if we take hold of what we can.

Since returning, Team Smoked Salmon have continued their role as leaders, such as through participating in the BC Health Regulators 2019 Spring Symposium on cultural safety and humility. This symposium involved leadership from BC's 21 health regulatory colleges and boards. Team Smoked Salmon students contributed to tabletop exercises with their future colleges and gave a very well received presentation about their experiences.

Evan (Mentor): Sometimes health training is very cold. Indigenous students are lost to attrition or drop out without realizing that their thoughts are needed, their contributions are needed, and their professions and patients need them. It is not that they don't fit the work, but that work in the mainstream system has not allowed them to be their authentic selves - both Indigenous and a health professional or trainee. The Challenge experience showed Team Smoked Salmon that they are needed in their professions. It took hard work and humility from them to work together, respecting the different perspectives that they brought, but they did it. As the only Indigenous physician among the mentors, I wanted all the students to see that they could be their authentic selves, be Indigenous, and be proud. 


\section{Conclusion}

Each partner in BC's health ecosystem, including postsecondary institutions, regulatory bodies, health authorities, and professional associations, play an important role in nurturing First Nations and Indigenous health professionals as part of commitments made at federal and provincial levels.

Team Smoked Salmon students reflected how participating in the 2018 International Indigenous HealthFusion Team Challenge was transformative to their individual learning journey, helping them feel equipped to continue their studies as leaders of change-empowered, excited, and confident moving forward. The Challenge provided an opportunity for future Indigenous health leaders to apply their disciplinary and Indigenous knowledges in a setting that was both challenging and supportive. The format demonstrates how BC's health and academic systems can create opportunities to develop the capacity of Indigenous health leaders and professionals as well as build cultural safety and humility.

First Nations and Indigenous students in health fields represent the future of a health and wellness ecosystem in BC that can bring together the best of Indigenous healing and mainstream approaches. Opportunities for students to step into their roles as Indigenous health leaders are currently few and far between. Creating opportunities for First Nations and Indigenous students to build their capacity as health leaders is an important part of reconciliation and the new relationship represented by the BC First Nations Health Governance Structure.

\section{References}

British Columbia Assembly of First Nations, First Nations Summit, Union of British Columbia Indian Chiefs, \& Province of British Columbia. (2006). The Transformative Change Accord: First Nations Health Plan: Supporting the health and wellness of First Nations in British Columbia.

http://www.health.gov.bc.ca/library/publications/year/2006/first_nations_health_impleme ntation_plan.pdf

British Columbia Ministry of Health, First Nations Health Authority, \& First Nations Health Council. (2011). British Columbia Tripartite Framework Agreement on First Nation Health Governance. https://www.fnha.ca/Documents/framework-accord-cadre.pdf

Curtis, E. (2016). Kohi Maramara: The effect of tertiary recruitment, admission, bridging/foundation education and retention on Indigenous health workforce development [Doctoral dissertation, University of Auckland]. University of Auckland Research Repository, ResearchSpace. http://hdl.handle.net/2292/30663

First Nations Health Authority. (n.d.). First Nations Perspective on Health and Wellness. http://www.fnha.ca/wellness/wellness-and-the-first-nations-health-authority/first-nationsperspective-on-wellness

First Nations Health Authority. (2016a). Health careers guidebook. http://www.fnha.ca/Documents/FNHA_health_careers_guidebook.pdf 
First Nations Health Authority. (2016b). \#itstartswithme: FNHA's policy statement on cultural safety and humility. https://www.fnha.ca/documents/fnha-policy-statement-culturalsafety-and-humility.pdf

First Nations Health Authority \& Assembly of First Nations. (2013). Our story: The made-in-BC tripartite health transformation journey. http://www.fnha.ca/documents/fnha_our_story.pdf

First Nations Health Authority \& First Nations Health Council. (2011). British Columbia First Nations perspectives on a new health governance arrangement: Consensus paper. http://fnhc.ca/pdf/FNHC_Consensus_Paper_-_WEB.pdf

First Nations Health Authority \& First Nations Health Council. (2012). Consensus paper 2012: Navigating the currents of change-Transitioning to a new First Nations Health Governance Structure. http://www.fnhc.ca/pdf/Consensus_Paper__Navigating_the_Currents_of_Change_(approved_for_distribution_May_7_12).pdf

First Nations Leadership Council, Government of Canada, \& Government of British Columbia. (2007). Tripartite First Nations Health Plan. http://www.fnha.ca/Documents/TripartiteFNHealthPlan.pdf

Government of British Columbia, Government of Canada, \& First Nations Leadership Council. (2005). Transformative Change Accord. https://www.fnha.ca/Documents/transformative_change_accord.pdf

Reading, C. (2015). Structural determinants of Aboriginal Peoples' health. In M. Greenwood, S. de Leeuw, N. M. Lindsay, \& C. Reading (Eds.), Determinants of Indigenous Peoples' health: Beyond the social (pp. 3-15). Canadian Scholars' Press.

Truth and Reconciliation Commission of Canada. (2015). Honouring the truth, reconciling for the future: Summary of the final report of the Truth and Reconciliation Commission of Canada. http://www.trc.ca/assets/pdf/Honouring_the_Truth_Reconciling_for_the_Future_July_23 _2015.pdf 